\title{
86. Crystal Structure of Bronzite from Chichi-jima in the Bonin Islands.
}

\author{
By Katsutoshi TakanÉ. \\ Institute of Mineralogy, Petrology and Economic Geology, \\ Tohoku Imperial University.
}

(Cơmm. by S. KôzU, M.I.A., July 12, 1932.)

The present investigation forms a part of the petrological study of boninite being carried on in our Institute under the guidance of Prof. S. Kôzu. The bronzite crystals used for the present experiment are the phenocrysts of boninite, which constitutes an islet called Chichi-jima in the Bonin Islands in the Eastern Pacific. Until recently, it has been a difficult problem for mineralogists and petrologists to determine which choice would be more reasonable for the optical orientation of the crystal in relation to the crystallographic axes which have been given hitherto in two different ways, that is, " $a$ " and " $b$ " interchanged. Besides we could not have any exact idea why the orthorhombic pyroxene must be grouped into a mineral family with the monoclinic one. Light has been thrown on these questions by recent X-ray studies on minerals by several investigators such as Merwin, Washington, Wyckoff, Gossner, Bragg and Warren, especially the last named author who has published an excellent result in regard to these problems. He succeeded in his study in introducing the diopside structure into the enstatite. In our case, the investigation started from the micropetrological point of view in order to determine the optical orientation in relation to its morphology and at first we examined the crystal in detail chemically and optically and then analyzed it by $\mathrm{X}$-rays in the following manner.

The axial ratio obtained by the Laue spots:-A thin plate of the crystal with a thickness of about $0.5 \mathrm{~mm}$., cut perpendicular to the greatest elasticity axis $\mathrm{X}$ of the mineral, was made for the present Laue photographic experiment. As the source of the X-rays, a Coolidge tube with a tungsten anticathode was used. From the gnomonic projection drawn from a Laué photograph and from results finally arrived at, the crystallographic axis "a " was reasonably found in parallel with the mean elasticity axis $Y$, and also with the aid of reflections obtained by the rotation method, the indices of the crystal faces appearing on the gnomonic projection were determined. The distance between the photographic plate and a position in the mineral at which X-ray diffraction effectively occurs, was determined by a method used in our previous study for topaz and it was $50.50 \mathrm{~mm}$. in this case. The axial ratio of the crystal found by the usual method of calculation, using the data obtained by the present method, is as follows:

$$
a: b: c=2.0537: 1: 0.5864 \text {. }
$$

Unit cell and the number of molecules in it:- -The axial lengths 
No. 7.] Crystal Structure of Bronzite from Chichi-jima in the Bonin Islands. 309

of the unit cell were determined from the photographs obtained by rotation and $18^{\circ}$-oscillation of the mineral prisms of about $0.3 \times 0.4 \times 3.0 \mathrm{~mm}$., cut parallel with the three crystallographic axes. As the source of the X-rays, a Hadding-Siegbahn metal-porcelain tube attached with a $\mathrm{Cu}$-anticathod was used. From layer line distance, especially from zero-layer lines corresponding to $(h 00),(0 k 0)$ and $(00 l)$, the dimensions of the unit cell were calculated as follows:

$$
\mathrm{a}_{0}=18.16 \AA \quad \mathrm{b}_{0}=8.84 \AA \quad \mathrm{c}_{0}=5.19 \AA
$$

From the above figures, the aixal ratio can be obtained as $a: b: c=2.0543: 1: 0.5871$, and we see that this result is in accordance with that obtained by the Laue spots within the experimental error.

The number of molecules present in the unit cell is found from the formula $n=(\mathrm{V} \rho \mathrm{N}) / \mathrm{M}$, in which $\mathrm{V}=$ volume of unit cell, $\rho=$ density of crystal, $\mathrm{N}=$ Avogadro constant, and $\mathrm{M}=$ molecular weight. According to Prof. Kôzu and his assistant Kawano, the bronzite under consideration is an isomorphous mixture of $15.5 \mathrm{FeSiO}_{3}$ and $84.5 \mathrm{MgSiO}_{3}$. Hence its molecular weight is $\mathrm{M}=0.15 \mathrm{Fe}+0.85 \mathrm{Mg}+\mathrm{SiO}_{3}=105.4$. The density measured by a pycnometer is given as 3.343 at $19^{\circ} \mathrm{C}$ or 3.337 at $4^{\circ} \mathrm{C}$. From these figures, we can know by calculation that 16 molecules of $15.5 \mathrm{FeSiO}_{3}+84.5 \mathrm{MgSiO}_{3}$ are present in the unit cell.

Space group:-According to Daly, in his study on the etching figures of the pyroxene group, the bronzite belongs to the orthorhombic holohedral class. From several photographs taken by three different methods, that is, Laue, rotation, and $18^{\circ}$-oscillation, we can observe the following relations between the indices:

$$
\begin{aligned}
(h k l) & h+k+l & =\text { odd } \text { and even } \\
(0 k l) & k+l & =\text { odd } \text { and even } \\
(h o l) & h+l & =\text { odd and even } \\
(h k o) & h+k & =\text { odd and even }
\end{aligned}
$$

Hence it is concluded that the three kinds of space $\Gamma_{0}^{\prime}, \Gamma_{0}^{\prime \prime}$ and $\Gamma_{0}^{\prime \prime \prime}$ can be omitted and only one kind of simple lattice $\Gamma_{0}$ remains for the present consideration.

In $(h 00),(0 k 0)$ and $(00 l), h, k$ and $l$ are always even. Besides, in $(h k 0),(o k l)$ and $(h o l)$, the following conditions can be seen:

$(h k 0) \quad h+k=$ odd and even, but $h$ is always even,

$(o k l) \quad k+l=$ odd and even, but $k$ is always even,

(hol) $\quad h+l=$ odd and even, but $l$ is always even.

Hence we may conclude that the space group of this mineral must belong to $\mathrm{V}_{h}^{15}$. 
The arrangement of the atoms:-As already stated, the bronzite crystal contains 16 molecules of $(\mathrm{Mg}, \mathrm{Fe}) \mathrm{SiO}_{3}$ in its unit cell. In this space group $V_{h}^{15}$, an atom is in general distributed at 8 positions, satisfying the symmetry elements. Hence there must be 2 sets of $(\mathrm{Mg}, \mathrm{Fe}), 2$ sets of $\mathrm{Si}$ and 6 sets of $\mathrm{O}$ in the unit cell, grouping in such a way as $8(\mathrm{Fe}, \mathrm{Mg})_{\mathrm{I}}, 8(\mathrm{Fe}, \mathrm{Mg})_{\mathrm{II}}, 8 \mathrm{Si}_{\mathrm{I}}, 8 \mathrm{Si}_{\mathrm{II}}, 80_{\mathrm{I}}, 80_{\mathrm{II}}, 80_{\mathrm{III}}, 80_{\mathrm{IV}}$, $80_{\mathrm{v}}$, and $80_{\mathrm{VI}}$, the origin being taken at the symmetry centre in this space group.

In oder to determine the co-ordinates, the tetrahedral corner arrangement of $4 \mathrm{O}$ surrounding $\mathrm{Si}$ and the distorted octahedral corner arrangement of 60 surrounding $\mathrm{Mg}$, suggested by Bragg, were taken into fundamental consideration. We can easily see that $c_{y}=5.19 \AA$ in the unit cell is practically double, compared with the $\mathrm{O}-\mathrm{O}$ distance $(2.6 \AA)$ along the edge of the oxygen tetrahedron. So it can be reasonably considered that two tetrahedrons of the O-Si group, whose one edge is parallel to " $\mathrm{c} "$, are linked in the unit cell and that the $\mathrm{O}-(\mathrm{Fe}, \mathrm{Mg})$ group must be placed in the intermediate positions between the O-Si groups in a manner to satisfy the symmetry elements in $V_{h}^{15}$.

To get an idea of the positions of the heavy elements, we examined at first the reflections from $(h 00)$ and saw that their intensities from (200), (600), (1000), (1400), (1800) and (2200) were very weak and those from $(400),(1200),(1600)$ and $(2000)$ were very strong. From the amplitude contribution $\mathrm{F}=8 \sum f \cos h \theta_{1}$, it is clear that the intensities of reflections from ( $h 00)$ must be strong when $h=4 \mathrm{n}$ and weak when $h=2 \mathrm{n}$. Hence we know that the heavy elements must be placed at $\theta_{1}=45^{\circ}$. The weak reflection from (1000) and the strong one from (1200) indicate that the heavy elements must occupy the positions of about $10^{\circ}, 45^{\circ}$ and $80^{\circ}$.

From the weakness or absence of the intensities corresponding to (002), (006), (402), (602) and (802) and from the results of the calculation of the amplitude contributions $(\mathrm{F})$, it is known that the values of $\theta_{3}$ for the heavy elements must be taken as about $15^{\circ}, 45^{\circ}, 105^{\circ}$, and $135^{\circ}$. Among these figures, it is clear from the symmetry relations in $\mathrm{V}_{b_{2}}^{15}$ that $45^{\circ}$ and $135^{\circ}$ can not occur at the same time.

For the determination of $\theta_{2}$, no suitable reflection from $(0 k 0)$ could be observed in the photographs. However we noticed that the relation $\theta_{2 i}+\theta_{2 i}=180^{\circ}$ can exist not only in the same kind of atoms but also in different ones, when we compare the experimental results and the calculated values of $\mathrm{F}$ relating to $(10,2,0)$ and $(12,1,0)$. Taking in consideration this relation and the co-ordinates $\theta_{1}$ and $\theta_{3}$ given above, 
No. 7.] Crystal Structure of Bronzite from Chichi-jima in the Bonin Islands. 311 the approximate values of $\theta_{2}$ were graphically obtained, using the average diameters of the stoms. The results are given in Table I.

TABLE I.

\begin{tabular}{|c|c|c|c|c|c|c|}
\hline & \multicolumn{2}{|c|}{$\theta_{1}$} & \multicolumn{2}{|c|}{$0_{2}$} & \multicolumn{2}{|c|}{$\theta_{3}$} \\
\hline & Takané & Warren & Takané & Warren & Takané & Warren \\
\hline$(\mathrm{Mg}, \mathrm{Fe})_{\mathrm{I}}$ & $45^{\circ}$ & $45^{\circ}$ & $120^{\circ}$ & $120^{\circ}$ & $135^{\circ}$ & $135^{\circ}$ \\
\hline$(\mathrm{Mg}, \mathrm{Fe})_{\mathrm{II}}$ & 45 & 45 & -15 & $-1:$ & 135 & 135 \\
\hline Sir & 8 & 10 & -125 & -126 & 105 & 104 \\
\hline $\mathrm{Si}_{\mathrm{II}}$ & 82 & 80 & -55 & -55 & 15 & 16 \\
\hline $\mathrm{O}_{\mathrm{I}}$ & 22 & 20 & 45 & 50 & 75 & 72 \\
\hline $\mathrm{O}_{\text {II }}$ & 22 & 22 & 185 & 180 & 75 & 72 \\
\hline $\mathrm{O}_{\mathrm{III}}$ & 15 & 18 & -90 & -90 & 15 & 17 \\
\hline$O_{\text {IV }}$ & 68 & 70 & 136 & +125 & 15 & 20 \\
\hline $\mathrm{O}_{\mathrm{Y}}$ & 68 & 68 & 0 & & 15 & 18 \\
\hline $\mathrm{O}_{\mathrm{VI}}$ & 75 & 72 & -90 & -90 & 105 & 108 \\
\hline
\end{tabular}

Comparing the F-values obtained by calculation using the co-ordinates given in Table I with the observed 72 intensities, we see that there are approximate coincidences between them but slight corrections on the co-ordinates, especially on those of oxygen, are necessary. If we take the values of the co-ordinates of enstatite given by Warren, the relation between the $\mathrm{F}$-values and the intensities observed by us are shown more satisfactorily as is seen in Table II. So we may arrive at the conclusion that his co-ordinates are suitable even for the bronzite whose chemical composition is given above, so far as the present X-ray analysis goes. In Table II, only the data relating to the pinacoids are given because the space of this publication is limited, and a fuller description will be given in the Science Reports of Tohoku Imperial University in the near future.

In conclusion, the writer wishes to express his hearty thanks to Prof. S. Kôzu for his kind guidance throughout the course of the present investigation.

\begin{tabular}{|c|c|c|c|}
\hline \multirow{2}{*}{$h k l$} & \multicolumn{2}{|c|}{ Calc. F. } & \multirow{2}{*}{$\begin{array}{l}\text { Obs. } \\
\text { inten. }\end{array}$} \\
\hline & Warren & Takané & \\
\hline $\begin{array}{r}200 \\
400 \\
600 \\
800 \\
1000 \\
1200 \\
1400 \\
1600 \\
1800 \\
2000 \\
2200\end{array}$ & $\begin{array}{r}0 \\
-\quad 43 \\
0 \\
-\quad 42 \\
0 \\
-253 \\
0 \\
+\quad 83 \\
0 \\
+121 \\
0\end{array}$ & $\begin{array}{r}0 \\
+\quad 31 \\
0 \\
1 \\
0 \\
-230 \\
0 \\
+\quad 97 \\
0 \\
-126 \\
0\end{array}$ & $\begin{array}{l}\text { Abs. } \\
\text { W. } \\
\text { V.W. } \\
\text { Abs. } \\
\text { Abs. } \\
\text { V.S. } \\
\text { V.W. } \\
\text { S. } \\
\text { V.W. } \\
\text { V.S. } \\
\text { V.W. }\end{array}$ \\
\hline $\begin{array}{r}020 \\
040 \\
060 \\
080 \\
0100\end{array}$ & $\begin{array}{l}+9 \\
-24 \\
+213 \\
+30 \\
-140\end{array}$ & $\begin{array}{r}-27 \\
-\quad 32 \\
+157 \\
+\quad 61 \\
-112 \\
\end{array}$ & $\begin{array}{l}\text { Abs. } \\
\text { M.W. } \\
\text { V.S. } \\
\text { M.W. } \\
\text { S. }\end{array}$ \\
\hline $\begin{array}{l}002 \\
004 \\
006\end{array}$ & $\begin{array}{l}-4 \\
-\quad 17 \\
-\quad 9\end{array}$ & $\begin{array}{r}0 \\
+\quad 9 \\
0\end{array}$ & $\begin{array}{l}\text { V.W. } \\
\text { V.W. } \\
\text { V.W. }\end{array}$ \\
\hline
\end{tabular}

TABLE II. 